\title{
Transition Spaces in an Indian Context
}

\author{
By Anjali Sadanand ${ }^{*} \& R . V$. Nagarajan ${ }^{*}$
}

\begin{abstract}
Architectural spatial organization is a manifestation of our socio-cultural character reflected in space. On one hand we have multiple users and on the other hand multiple functionally defined spaces. Differences in social relationships are reflected in the articulation of spaces. In this sense the significance of transition spaces is paramount. The paper aims to explore the nature of transition spaces with respect to social meanings attributed to them and the symbolic reference they give in return to architectural space. The transition from public to private, from sacred to profane is explored. It aims to describe transition space in terms of nature, character, morphology and social meaning. Hierarchy and enclosure will be looked at, as well as transparency and material articulation. From architectural elements to spaces, the role and quality of the nature of "transition" will be analysed. The paper will look at transition spaces from the viewpoint of its role, as that, which enforces the identity of users and from that, which merges them. Social conditions of status, gender and differentiation will be enumerated. Transition spaces from examples of houses in traditional environments, urban and rural will be described and compared with corresponding urban and contemporary examples within a fixed historical framework. The study will concentrate on examples from South India. Focus will be given on threshold spaces and courtyards. Theoretical framework of Yatin Pandya will be referenced in terms of spatial elements and Amos Rapoport for a framework of reference for social meaning and space. The paper will show that in contemporary life people adapt to new conditions but maintain old traditions interpreted in a new way where distinct boundaries laid by tradition, give way to new understandings of adjustment and adaptation and temporal space thereby to some extent blurring boundaries but still maintaining cultural differences.
\end{abstract}

\section{Introduction}

There has been much written on vernacular architecture in the North of India, V.S. Pramar, Kulbushan Jain, Yatin Pandya, to quote a few authors. They describe vernacular settlements and housing with details on materials and use. Some articles have been published on coastal villages and villages in the Thanjavur and Kumbakonam area. However, the focus has been on climatological and sustainable features. They describe vernacular settlements and housing with details on materials, climatic performance with descriptions of social use.

South India has a vivid history dating to the Sangam period as far back as 300AD and has a rich cultural heritage presented in the numerous temples built by the Cholas and Pallavas. Settlements arose around temples and were carefully planned within the norms set down by rules dictated by traditional building codes.

\footnotetext{
*Associate Professor, MEASI Academy of Architecture, India.

tProfessor, Hindustan University, India.
} 
South India has a caste system and hierarchy in caste was spatially manifested in settlement plans and houses. House design of these settlements gave rise to an origin of secular architecture in South India within the framework of traditional norms respecting differences and manifesting them through their architectural articulation. Within them there were typologies based on size and shape. The paper looks at Agraharam houses, those occupied by Brahmins. The scope of the paper is to study transition spaces in samples in the rice bowl of South India, Tanjore, Kumbakonam and in Chidambaran and urban Chennai. "Agraharam means front or foremost row implying a prestigious location." It is an exclusively Brahmin neighbourhood or settlement. Brahmins were landowners and life in an agrarian society was ritual based and revolved around festivals based on the moon. Families were brought together and a sense of community enhanced through functions for propitiating the Gods on festival days. The Hindu joint family was the basic unit and houses were designed to satisfy needs of different genders and generations with provisions for feasts and celebrations such as weddings, etc. Birth and marriage were celebrated in the house. The house had to spatially accommodate both the everyday functions and the requirements for festival days without compromise. In this light, the in-between or transition spaces seem important as spaces which permit dualities, as well as join the different realms. The paper aims to first understand the nature and kinds of transition space in terms of its spatially, form significance and describe its function in maintaining social relations, as well as question and explore the nature of its transformation under different conditions such as in an urban context and in more modernized houses. The scope of the study is limited to 8 examples from rural and urban areas in Tamil Nadu. The paper restricts its discussion to the articulation of transition spaces.

\section{Literature Review}

\section{Definitions}

Transition space can be defined as a space between two realms. They are transformative spaces that introduce discontinuity by creating and end and suggest a beginning. They enforce dissolution, create layering and disassociation. The threshold space is a transition space and can be situated between inside and outside, between different spaces inside or be situated entirely outside. "The phenomenon of the threshold thrives on spatial ambivalence." 2 A threshold space can be a space that defines the entry of a major space, it can exist as a space that connects two spaces or it can be a space that is an ante space, a spatial preface to a functional room. In the Indian context the transition space is a significant space as it symbolizes the passage between two distinct realms. "The threshold expressive of transition, has always received special attention from Indian builders of the past. Even today, ceremonies on all important occasions include a special event

1. M. Desai, Wooden Architecture of Kerala (India: Mappin Publishing, 2018), 117.

2. T. Boetteger, Threshold Spaces (Basel: Birkhauser, 2004), 10. 
connected with the threshold, which in many cases is decorated and worshipped every day." "The essence of a threshold space is capturing and staging an entrance." "Man is the centre and forms at every point the starting point.",

\section{Space in the Indian Context}

Yatin Pandya in "Elements of Spacemaking" suggests a framework for looking at architectural elements in transition spaces in terms of physical articulation. Yatin Pandya does not discuss the courtyard or other typical structures, found in Indian architecture, but restrains his discussion to the following architectural elements-of Floor, column, Wall, Door, window, stair and Roof with examples from the Indian vernacular in North India. Considering the commonality of such references to South India, Yatin Pandya's book has been thought of being proficient to suggest elements common to both North and South India. "The Sanskrit word for floor is bhutal where bhu refers to the earth or ground, it also means "to exist" and tal refers to the bottom or base surface. Floor essentially delineates territory." In the Indian context the floor is particularly significant. As we sit on it and eat on utensils placed on the floor. A modulated floor of ups and downs gives a seat. The thinnai uses this concept (Figure 1). Space is defined in a floor by virtue of decoration which in turn is symbolic and communicates significance. A transition from one space to another is manifested on a floor as level change (Figure 2). The perception of floors in sequence defines pause and movement. Floor as a raised plinth can demarcate reference datum and territory, inside and outside (Figure 3). The column is a support, a point in space and a row of columns suggest direction and can be perceived to define space and form a guide for movement (Figure 4). The column is an image maker and marker of space, with special reference to vernacular columns which are decorated in colors with carved capitals and brackets in timber.

Pandya states that it is a threshold between public and private and an image maker. He says windows are elements that also offer transition. He concludes with stairs. Steps are thresholds and can be seats (Figure 3). The roof, he says is an image maker and modulator of volume with no reference to a correspondence between function and roof type. Pandya restrains his discussion to the following elements discussed above.

\footnotetext{
3. K. Jain, Thematic Space in Indian Architecture (New Delhi: India Research Press, 2002), 72.

4. Ibid, 66.

5. Ibid.

6. Y. Pandya, Elements of Spacemaking (India: Mappin Publishing PvtLtd, 2007), 14.
} 


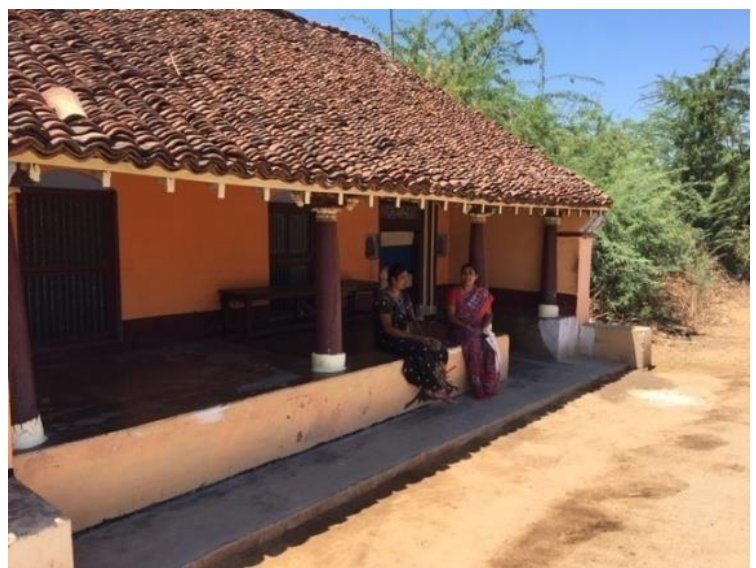

Figure 1. The Raised Seating Area Called Thinnai Source: Anjali Sadanand.

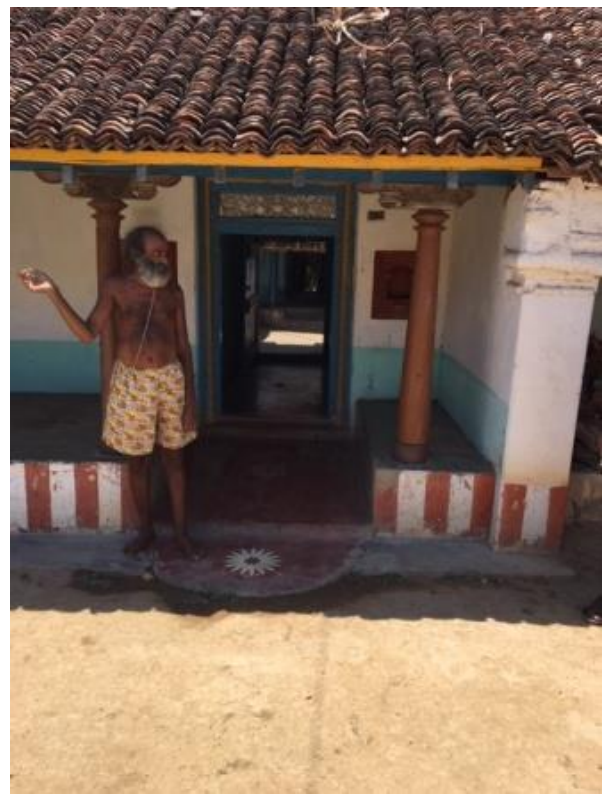

Figure 2. Kolam on Floor - Entry Source: Anjali Sadanand.

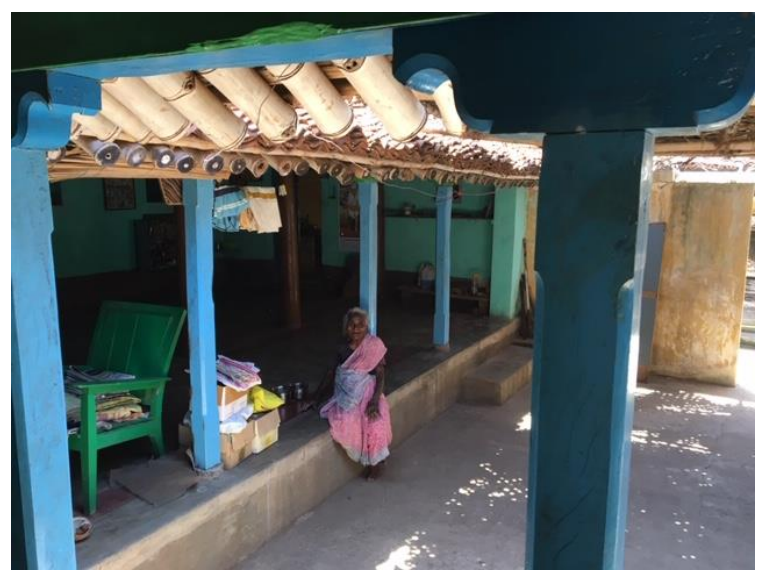

Figure 3. Transition between Inside and Outside Source: Anjali Sadanand. 


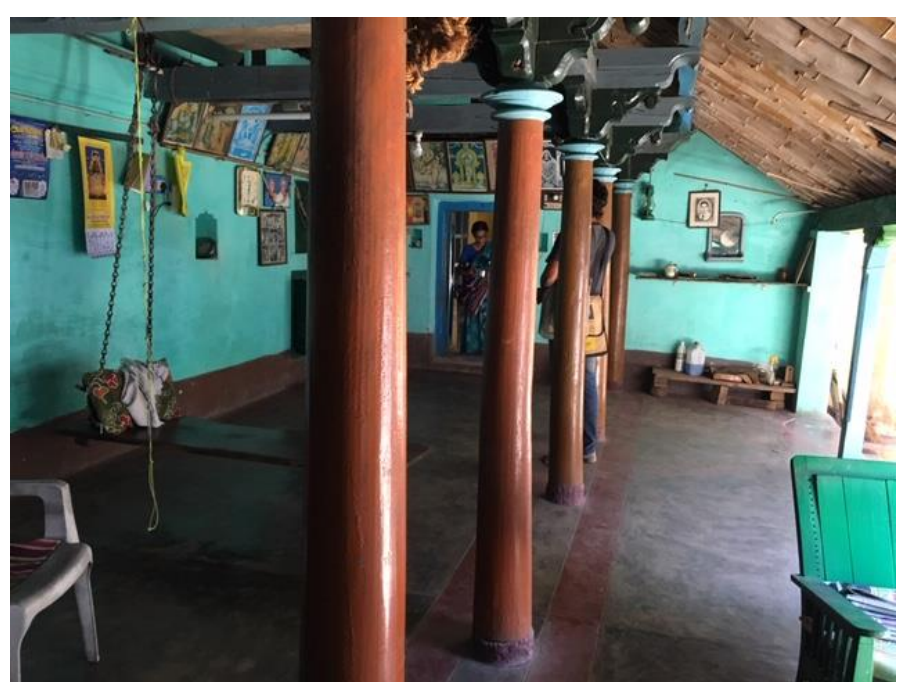

Figure 4. Columns as Direction and Delineation

Source: Anjali Sadanand.

Walls are protective barriers and used in the vernacular to store things. "The door connotes an act of passage between two realms." In Thematic spaces, Kulbushan Jain looks at "spatial themes that have a strong presence in Indian architecture. The intention is to also highlight the key factors that have played an important role in the evolution of spatial articulation." 8 The spatial themes are the pavilion, the courtyard, the in-between realm and the classical cave. Jain maintains that "the interplay of physical and the metaphysical determines the formation of architectural spaces." $"$ Courtyard spaces are the heart of houses and other spaces are in layers around them and they protect other spaces in terms of privacy. Household functions spill onto them in good weather daily activities spill out onto the courtyard, which is also gender based. Jain says "A courtyard's position becomes that of a principal space organizing element." "Courtyards offer light and ventilation and keep the dwelling cool. On transition spaces, Jain comments "the transition deals with the movement from one situation to another, from one set of space - light values to another." "Jain quotes "transition of thinnai in South India where two levels of thinnai spatialise differences. The inner layer of higher plinth is for higher caste." 12

In, a study on sustainable design principles: A case study of a vernacular dwelling in the Thanjavur region of Tamil Nadu, India. By P. Jayasudha, M. Dhanasekaran, Monsingh D. Devadas and N. Ramachandran in Indian Journal of Traditional knowledge, Volume 13(4) October 2014, a detailed study of social activities and spaces has been carried out with reference to space, social activity, user and thermal performance. The thrust of the discussion is on thermal comfort with data supported by Ecotect software analysis. However, the social activities

7. Ibid, 14.

8. Jain, Thematic Space in Indian Architecture, 2002, 8.

9. Ibid.

10. Ibid, 66.

11. Ibid, 72 .

12. Ibid, 74 . 
have been listed comprehensively and offer a guide for study of this kind in this paper.

In Strategy for Flexible Spaces in Housing - A Study With Reference To Agraharams in Kumbakonam, by Safrin Rex Dulcie J., in International Journal of Advance Research, Ideas and Innovations in Technology, 2017 (Volume 3, Issue 6) there is a comprehensive study of space, social use and flexibility in courtyard houses in a Thanjavur village. Description of house types are described based on courtyard locations of single courtyard houses She defines the types of courtyards according to their location and discusses spatial organization of the respective houses around the internal courtyards. The author argues technological advancement is reflected in new trends in the behavioural pattern of people and a desire to move away from traditional thinking patterns.

Significant takeaways are in the function of the courtyard as a transition space in different situations evident in the samples provided.

In an attempt to interpret pre-industrial vernacular architecture in UdaiyalurSamavad 2011 conference proceedings, Ahmedabad, the author concludes with the significance of the haptic experience brought on by light and material and comments on transitions and changing experiences in agraharam houses.

The author has drawn inferences from an appraisal of the vernacular dwelling from a study of space, social use, artifacts, elements such as columns etc., and decorative details that constitute the interior. She comments on typologies as being based on classification based on number of courtyards. Simpler houses, she writes have a single courtyard awhile more complex houses have three courtyards.

\section{The Hindu House}

The Hindu house has spaces decided on ancient knowledge based system which derives its rules from metaphysical and practical factors. "Vastu derived from the Sanskrit or vasa, to dwell, is the long established name given to localities suited for the habitation of human beings." ${ }^{\text {"Refer Figure } 5 .}$

"The Hindu concept of a house is that of the Universe as an ordered division of space ranging from vulnerable to sacred areas. There is a progression inward from the unstable to the stable, from the less pure to the pure. Pollution has to be kept at bay. This involves controlling access to the sacred space."

In this paper as suggested by Lindsay Asquith the anthropological and sociological approach will be used to study dwelling.

1. Spatial and activity patterns universal to a culture - an anthropological approach.

2. Those that are part of a daily routine and ritual - a sociological approach.

3. The formation of type she refers to as an architectural approach.

13. M. A. A. Ananthalwar, Indian Architecture (Chennai: V. T. Iyer \& sons, n.d.)

14. I. Cooper, and B. Dawson, Traditional Buildings of India (London: Thames and Hudson, 1998), 163. 
"Traditional buildings of India Because Vernacular environments are those most clearly linked to 'culture', they are essential in clarifying the ways in which culture and environments are related." 15 Norms of culture are expressed spatially in dwelling and the reading of cultural meaning in space is made possible. "A dwelling needs to be defined as a system of settings within which systems of activities take place."16

In House, Form and Culture, Rapoport suggests that there are three factors that determine vernacular architecture. They are socio-cultural, climatic and material and construction. Furthermore, he reiterates that socio-cultural factors in instances override climatic factors. He draws reference to this in relation to orientation and cosmology in relation to dwelling and settlement planning. He lists five socio-cultural factors:

1. Some basic needs

2. Family

3. Position of women

4. Privacy

5. Social intercourse ${ }^{17}$

Cultural norms determine behavior patterns. To support this, Hanson comments that "a house is not a list of activities of rooms, but it is a pattern of space, governed by intricate conventions about what spaces there are, how they are connected and sequenced, which activities go together and which are separated out." "In this respect the design of houses cannot become divorced from those that will eat, sleep, cook and play in them."19

"Concepts of spatiality are crucial to all cultures. "Place-making" has become a more amenable term of social relevance than the purist notions of space" and involves" Scenarios where people shape and define their own area. ${ }^{20}$ Desai argues that "place-making" has been suggested as a more humanist approach as a concept, in the context of built environments. Transition spaces ensure placemaking by establishing culture in space.

\section{Typology}

With regard to typical descriptions of Agraharam houses, the following describes a short evolution in development, from a simple structure to a complex

15. L. Asquith and M. Vellinga, Vernacular Architecture in the Twenty-First Century (Great Britain: Taylor and Francis, 2006), 183.

16. A. Raporport, House Form and Culture (USA: Prentice-Hall, 1969, 162).

17. Ibid.

18. J. Hanson, Decoding Homes and Houses (Cambridge: Cambridge University Press, 1998), 2.

19. Asquith and Vellinga, Vernacular Architecture in the Twenty-First Century, 2006, 129.

20. Desai, Wooden Architecture of Kerala, 2018, 165.

21. https://shodhganga.inflibnet.ac.in/bitstream/10603/38625/3/03_abstract.pdf.

22. Ananthalwar, Indian Architecture (n.d.), 61. 
multiple courtyard house with a large hall. First two typologies have openings in front and rear and through courtyards. The dwelling unit starts with one room to develop into a three room unit with a thinnai or front raised verandah, a hall called a koodam and a kitchen called a samayals. The thinnai is the front and male zone and public zone, the kitchen is the women's zone and private zone and the centre is the family and semi-private zone. The courtyard was the introduced to give light and ventilation and houses subsequently developed around their courtyards. "Typology 3 consists of dwellings with a central double height ceiling with clerestory upennings." 20

Another description enumerates the various parts of a typical house. "In South India, the custom is to provide for five well defined parts of a house:

1. Outer verandah intended to receive visitors.

2. The front hall where all rest at night.

3. Quadrangular structure with a courtyard in the centre; dining and religious observances here.

4. The kitchen, nursery and toilet requisites, practically women's quarters.

5. A long and open backyard of the house with well, bathing shed, latrine cow-shed, etc." 22

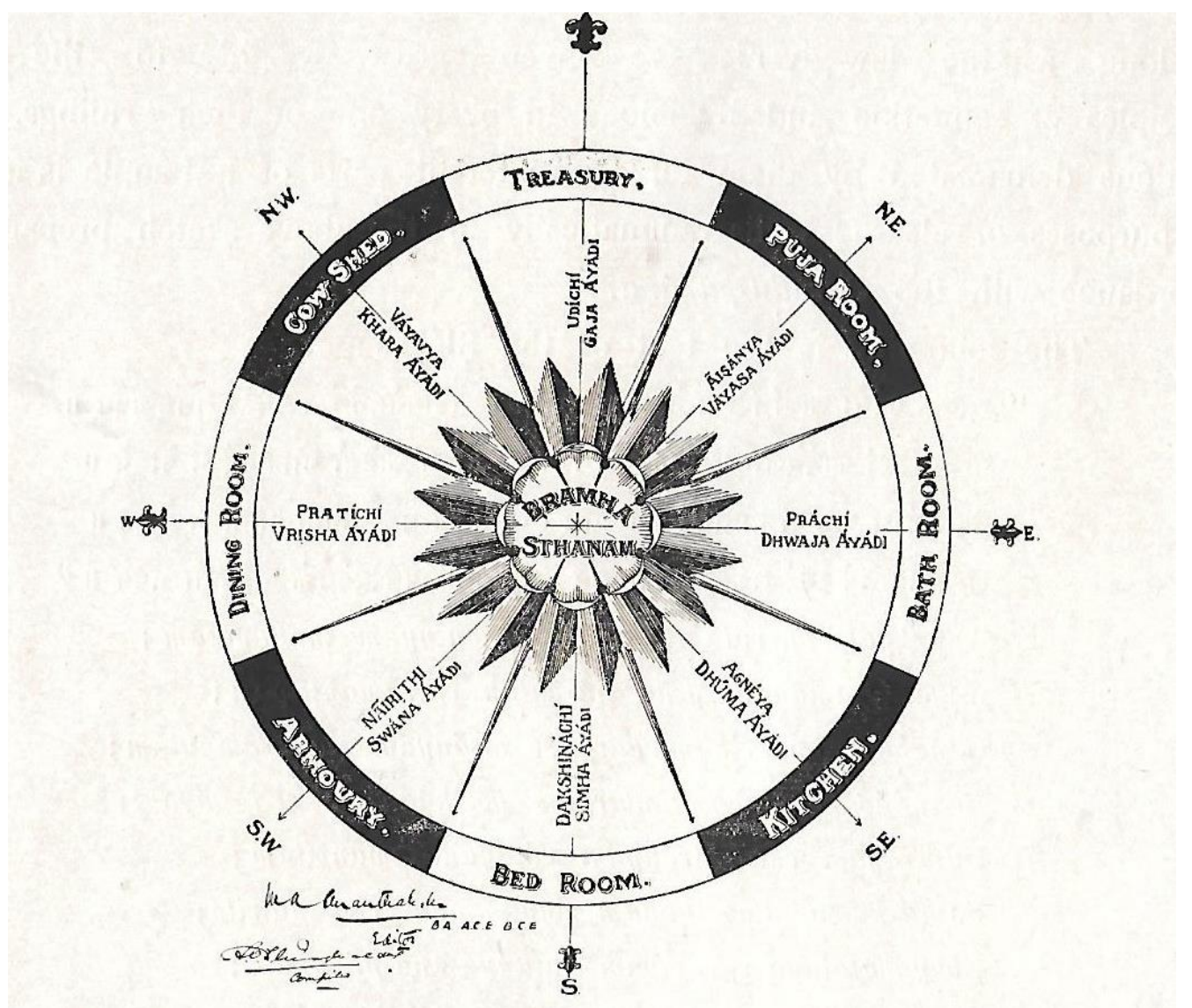

Figure 5. Space Arrangements in a House according to Sanat Kumara Grihavastu Source: M. A. A. Ananthalwar, Indian Architecture, n.d. 


\section{Methodology}

A sample of 8 houses will be studied in terms of the location of transition spaces and with the parameters stated. A comparative analysis of them will be conducted to arrive at conclusions and to therefore suggest types of transition spaces and to suggest those that have sustained themselves and have been retained in urban houses. Parameters to analyse transition spaces:

1. Spatial arrangement with relation to house and street.

2. Access and control. Sequence? Is the movement fixed or flexible?

3. How can the threshold space be defined with respect to scale i.e. width and length.

4. Phenomenological experience in terms of light and materiality.

5. Level of decoration, image ability and any distinct architectural elements or furniture equipment.

6. Its function and social use.

7. Its symbolic significance.

8. Types of transition spaces.

\section{Discussion}

\section{Sample Selection}

The sample of 8 houses has been selected based on two broad categoriestraditional and urban. With respect to the vernacular, the two villages selected have been studied by students as part of their academic rural documentation programme and furnish examples of houses atypical of the area and in good condition. However, many are sealed and inaccessible. Therefore, the sample comprises a few numbers. In the urban scenario the sample was chosen from what is available and representative of the theme of the paper. Reference is not made to area of each house as it is not considered significant to the study.

\section{List of Houses}

House 1 - Agraharam house of single courtyard in Chidamabaram, original and as converted by a couple who worked in a bank.

House 2 - Agraharam house of single courtyard bought by a Christian family and converted.

House 3 - Agraharam house of three courtyards.

House 4 - Agraharam house of three courtyards with additional rooms.

House 5 - Agraharam type house in Chennai.

House 6 - House built in 1960's which combines tradition with the contemporary Traditional dwelling converted to today's living conditions.

House 7 - Traditional dwelling converted to today's living condition.

House 8 - Contemporary House. 


\section{Description of Agraharam Houses and Comparision}

House 1 (plan in Figure 6), is a house accessible from an agraharam street in a village near Chidambaram town. The street leads to a temple. Houses have common walls and in the rear, is situated a backyard with a rear entrance. The house is south facing with a linear plan. Only the entry and a room face the street which gives it a narrow frontage. The window facing the street is sheltered by the thinnai. It has been planned following the traditional concepts of planning of Vaastu. The house serves as a home for a Hindu joint family of five to ten members. Social customs and behavior patterns though modified are adhered to. There is sparse furniture in the house as it is the custom to sit on the floor. Sitting on the floor is a practice even used for eating. Bedrolls are used for sleeping, which can be rolled up after use and stored away. In some houses there is a single bed or cot. A timber plank swing suspended from the ceiling beam in the hall is a common feature.

Lifestyle patterns are simple, as in, men go to work during the day and women are in the house performing duties. Women seldom go out on social occasions except for festivals and special social functions.

The rear part of the house can be zoned as being chiefly concerned with women's duties and the front part with men's social duties. A centrally located courtyard built with one side to the edge wall gives light and ventilation to the hall and space is organized around it. The house demonstrates a key feature of the vernacular house in its alignment of doors in an axis. This is called as the "Soma sutra." This Energy axis is a row of openings aligned in the same line. The NorthSouth energy axis, i.e. the front door facing, the rear door and the thinnai as a transition from street to house are aligned. The kitchen is accessible from the hall and as is customary the bathrooms are in the rear accessible from an outer verandah. The Hall is a multi-function space. Transition from public to semipublic happens through the thinnai area. Slippers can be left there. The thinnai with the doorway performs as a threshold between the profane outside world and symbolizes and spatialises the transition.

The second transition is the colonnade around the courtyard. The transition space is "C" shaped. This space is of neutral significance and functions as a corridor. The space can be traversed by all categories of people. It leads to the rear part of the plot that houses services such as well and cowsheds and bathrooms. This space leads to "impure" spaces and to the Hall. It is the transition between the Hall and the "ritually "impure" space. The kitchen and pooja which is located as a part of the kitchen are considered as sacred space. Rights to entry are therefore scrutinized and women during menses are considered unclean and hence not allowed inside these areas. The area adjacent to the kitchen serves as a living space for them with easy access to the outdoor, privy and accessible from the colonnaded space.

Within the house the transition space adjacent to kitchen precludes the service spaces beyond. In dealing with labourers this door and space is used.

The Chidambaram house represents the simplest form of understanding of transition spaces as delimiters of space. The space can be used for storage. Its 
primary role is to establish a threshold between two realms and thereby create significance and importance to the following space.

Alterations were made to House 1 by an urban couple, both of whom were bank employees, who decided to shift to a rural setting. They took over the house and renovated it. They were a small family of two people. Changes made, were as follows. The kitchen and puja were joined as one space and the ante room in the rear was converted to a bathroom. Rear rooms were left as is. The hall functioned as a living space with television and for social interaction. The thinnai was rarely used and people were invited inside the house but a thinnai seat was built. The kitchen was an open plan kitchen which functioned as a dining room in addition. The puja was a shelf in the kitchen so located that the God's faced east as considered auspicious. Entry remained through the thinnai, but the thinnai lost its function as a socialising space. It was retained as an ante space where you removed your footwear. Social hierarchy manifested in space and seen earlier ceased (Plan on the right in Figure 6).

Taboos related to pure and impure were removed and the bathroom was located within the house easily accessible from the hall. Spatially the house, in terms of the social relations it established, worked as a modern flat with the exception that the front room retained as a bedroom did not have an attached bathroom and functioned as the only sleeping space.

Subtle differences and articulations of steps and levels have been removed. Symbolic significance has been removed to give way to function and ease of living where proximity succeeds.
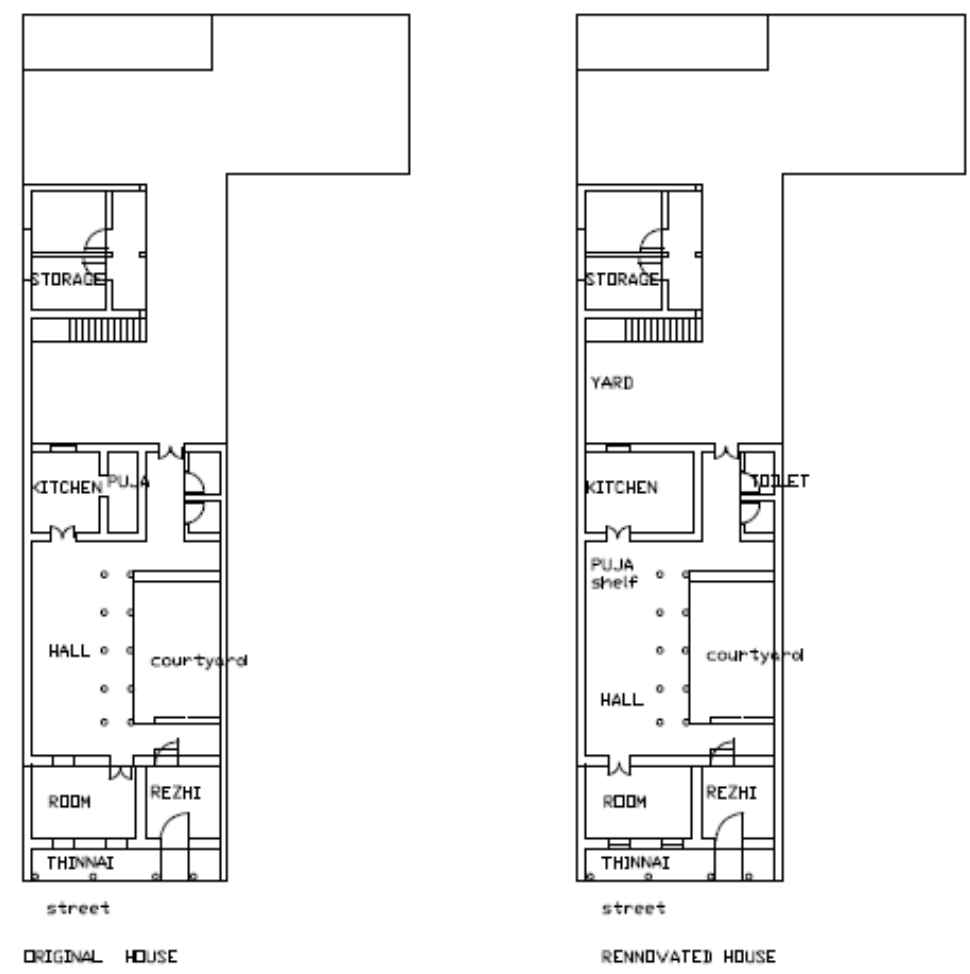

Figure 6. Chidambaram House Plans

Source: Anjali Sadanand. 
House 2 (Figure 7), is in a village with close proximity to Kumbakonam town, faces west and is an agraharam house. It is similar to House 1, as it is linear in plan but is more compact. It has a larger front room with two windows facing the street and therefore, a longer thinnai. The kitchen has a small skylight and there is a walled in backyard for services and a door leading beyond for the privy. From the front door, the door to the rear land is visible. In the context of agraharam houses this house is part of a settlement plan where houses are arranged around the temple. Its front door faces west. The kitchen is in north east and bedroom, a part of it is in south west. The courtyard's longer side faces south and ensures that the interior of the house is kept comfortable. The courtyard like in House 1 is aligned to the front door and creates a visual barrier from the outside. The hall is visually protected (Figure 8).

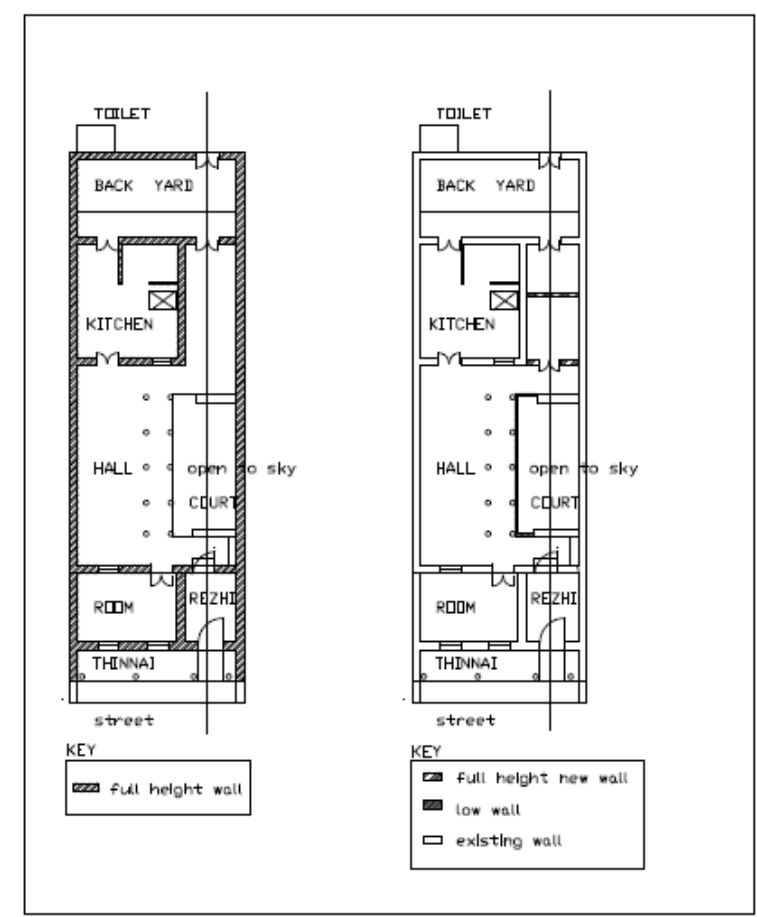

Figure 7. Plan of House 2 (Renovated House on the Right)

Source: Anjali Sadanand.

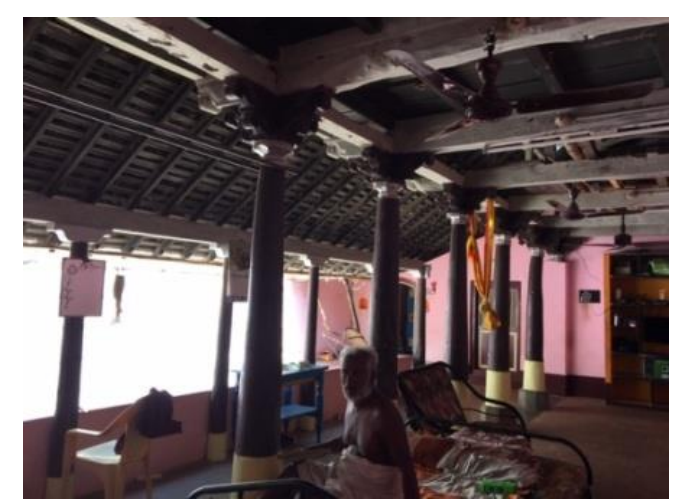

Figure 8. Hall in House 2

Source: Anjali Sadanand. 
A neighbor and an identical house of House 2, was renovated by a Christian family with young children. In agraharam houses you buy only one wall and they were offered the second wall as the house next door was being demolished. Their house shows the value placed by traditional Hindus on certain factors to do with orientation, purity and impurity and hierarchy. The first noticeable change is in the lack of significance given to the axis and the front door. The front door in the House now faces another closed door. The former ante- space, a transition to the outside, has been renovated to form a granary. There is no division of services in courtyards and the washing machine features as a piece of equipment with the fridge in the Hall. The hall is still the hub with social interaction and dining activities taking place there. Women are not relegated to specific areas of the house but can at all times enter all areas. The courtyard which was connected visually and physically construed the thalavaram as a transition between courtyard and hall becomes a delimited space by being contained within a small low wall. Access is only permitted on two sides and the thalavaram now becomes part of the hall and constitutes a differently articulated space by virtue of the rows of columns, but is part of the hall and can be perceived as an extension of it. Each space connects equally in a network of rooms. Definitive rooms emerge now and connect one another with blurring boundaries on the one hand as well as being spatially well defined on the other hand. What is retained is the location of the privy which remains outside and accessible only through the outer courtyard which acts as the threshold to the outside world. The thinnai is maintained and remains a social interaction space.

Subtle differences and articulations of steps and levels have been removed. Symbolic significance has been removed to give way to function and ease of living where proximity succeeds.

In House 3 (Figure 9), the plan is linear and extended. This agraharam house has 7 doors. Features of typical agrahram houses from house 1 and 2 are made more complex. Where House 2 gives a compact solution House 3 is spread out and each activity is given its own space. The house is built around three courtyards. Interface with the street is through the thinnai. The thinnai represents an area open on one side to the street and shaded by a low sloped roof. The height inside this area is not sufficient to stand upright. It is a place where men and women chat and interact with the outside world. It is cool as it is oriented to catch the breeze and in older days offered a place for strangers to rest. It is the most public space of the house. Once inside the threshold one bends to enter and walk over the strip of wood of the door frame before entering the "rezhi.' The door enclosure is very significant and features symbolic motifs of religious significance. It is seen to protect the house. The door frame of a house is fixed only on an auspicious day and time seen in the Hindu Almanac. Beyond the door the rezhi is a semipublic space. Its function is to give access. It is used for storage etc. In House 3 it has a thinnai seat and leads to the thalavaram. An outsider can be met at the thinnai area and if you are a family member or known person entry to the house is permitted and slippers can be left at a specified space in the rezhi or thinnai and only house members leave their slippers in the thalavaram. Like other houses, the front door is aligned to the back door. Two sets of transition spaces are visible. Interior 
transition space of thinnai, rezhi and thalavaram and first courtyard which leads to second courtyard, which has an ante space for women and then leads to a third ante space of a colonnade around a service courtyard leading then to a backyard. Courtyards act as transitions between women's spaces and men's spaces or family spaces. There is a sequence of transition spaces leading one to another and each establishing the significance of the space by creating an interval between realms and connecting them. Transition spaces of this nature maintain privacy and control of the rooms they lead to.

In House 3, transition is also articulated in the formation of levels between courtyards and can be seen in the detail of steps. Steps formalize transitions through behavior and engage the body in enacting the transition, as in the lower lintel heights of doorways which ensure you bend your body by lowering your head and enter. Sequential glimpses of the interior are thus offered which is orchestrated by the careful placement of openings and levels. The hall is the hub of the house and all activity is spatialised there. It is occupied throughout the day and protected on both sides from outsiders through the transition spaces that lead off to the rear door and front door. Women are given privacy this way and in the older days rank was maintained through these numerous transitions.

House 3 offers a series of courtyards each one establishing a zone from a front public zone, to a women's and a more private zone, to a series of service courtyards and finally connecting to the outside (Figures 10-12).

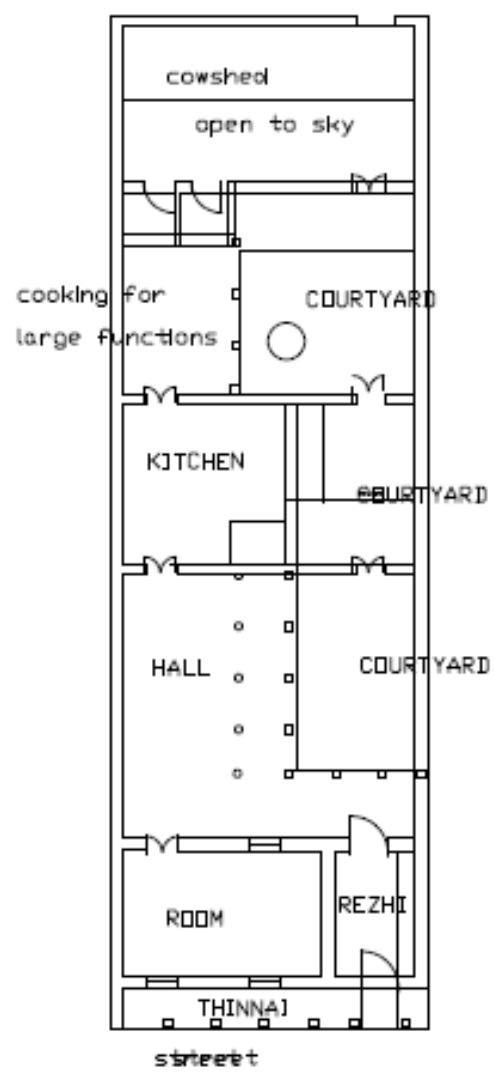

Figure 9. Plan of House 3

Source: Anjali Sadanand. 


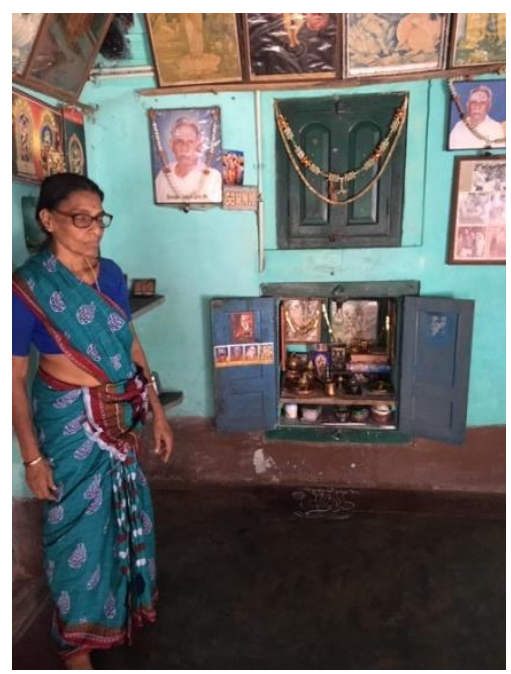

Figure 10. Puja in House 3

Source: Anjali Sadanand.

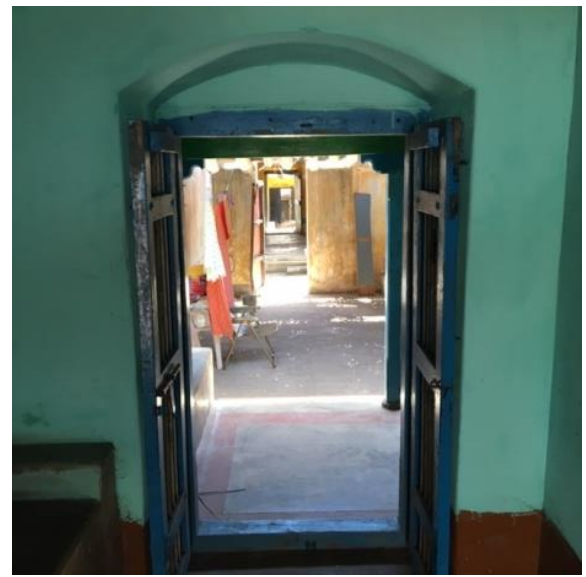

Figure 11. Doors in Axis in House 3

Source: Anjali Sadanand.

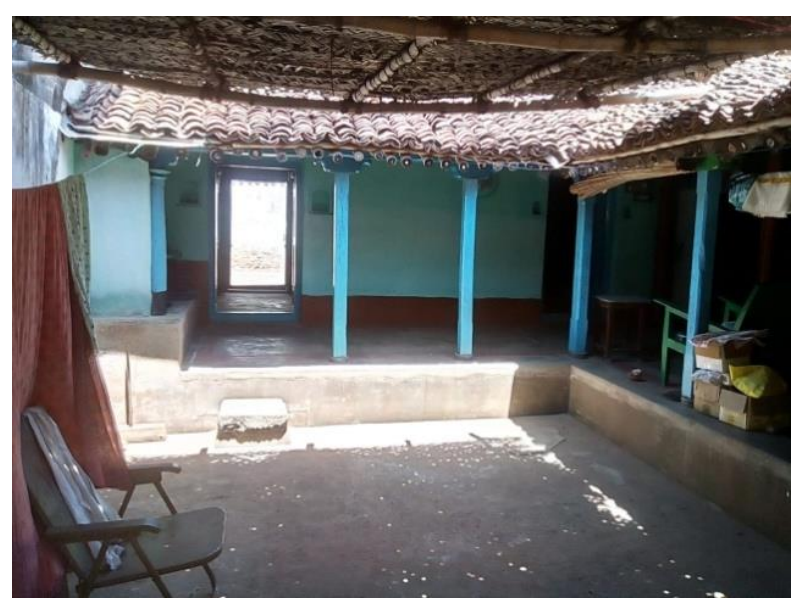

Figure 12. Looking from the First Courtyard Source: Architect Vidya Shankar. 
In House 4 (Figure 13) a more complex version of House 3 emerges. The major difference is that it caters to a large joint family and hence has to cater to more social complexities brought on by age and gender and provide a spatial programme that appropriately answers their needs. House 4 is an example of an original agricultural landowner's house in an Agraharam where the family now consists of members who are office workers. The thinnai takes the form of two seats on either side of the façade of the house to provide strangers with seating to rest. The space between them which is decorated with a kolam is the golai, Refer Figure 14, an area where grain is dried in the sun. The thinnai follows and is for social interaction and as it is south facing catches the breeze and occasionally used by men to sleep. The rezhi is the next transition and is the first space the front door opens on to.

On either side of the front door are two niches for oil lamps, to be lit as is customary in the evenings (Figures 14 and 15). Water as a purifier is believed in Hindu tradition and water is sprinkled in the golai first thing in the morning and a kolam is drawn, to protect the house symbolically and the same process is repeated in the and in the early evening when the lamps are lit at twilight. Transitions to the outside are always viewed as protection for the dwellers. The system of layering and sequence installs a slow progress into the interior and provides a psychological break with the outside world. The hall has a swing and is a cool space which transitions to the courtyard through the thalavaram (Figure 16). The thalavaram is the outside fringe of the interior hall.

For women during menses a separate room is provided off a transition space beyond the thalavaram. The thalavaram has been designed to accommodate an area for them to dialogue with the rest of the family and not enter the hall which has more significance. This space acts as a transition space for them and the family just as the thinnai acts as a space between the outside and the family.

The first courtyard contains the main spaces and the second courtyard the service spaces. Once again a sequence of transitions occur from public to semipublic, semi-private and private to once more gender oriented space sand semipublic space. In each case the nature of the transition upholds the quality and significance of the space. In today's world the family retains its cultural outside fringe of the interior hall.

In today's world the family retains its cultural rootedness by practicing these behavior patterns with the only difference being in their attitude to caste and religion, people of all caste and creed are allowed into their Hall which is fitted with a swing, a few chairs and a TV. 


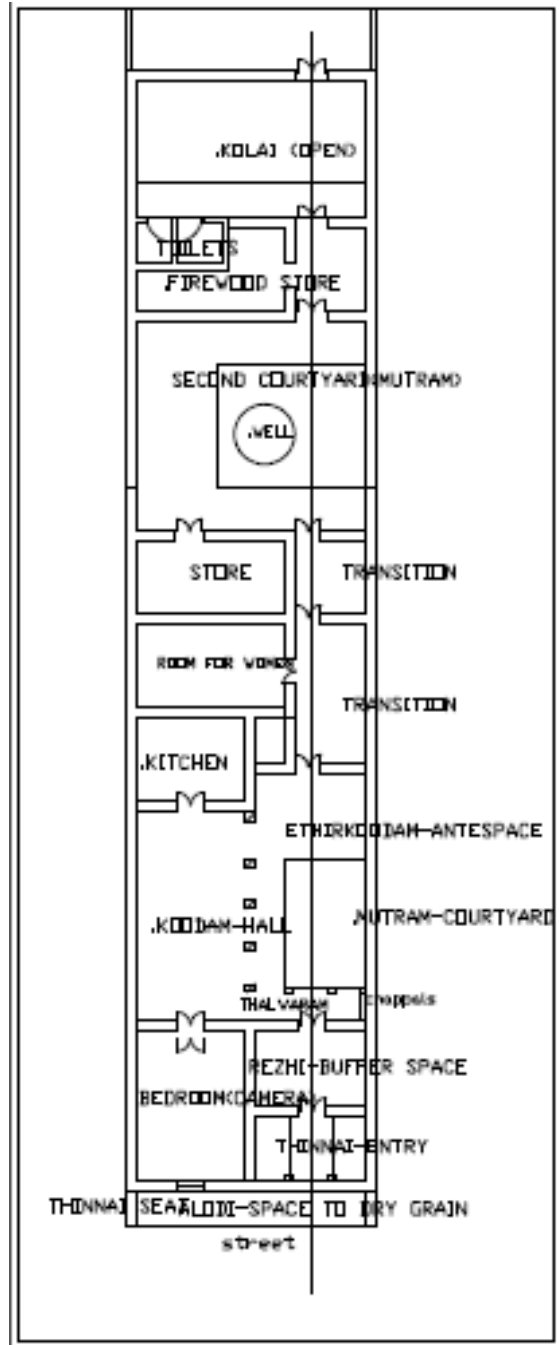

Figure 13. Plan of House 4

Source: Anjali Sadanand.

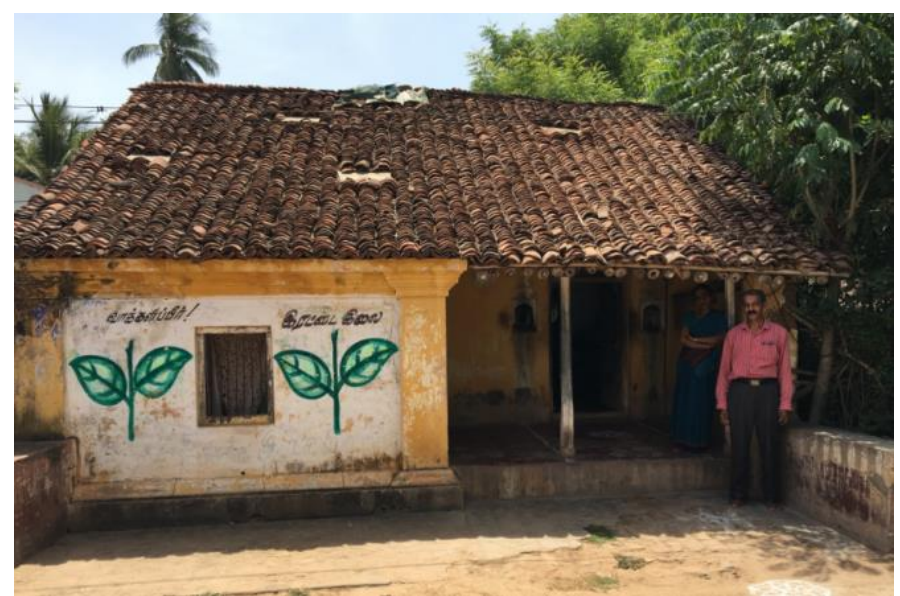

Figure 14. House 4

Source: Anjali Sadanand. 


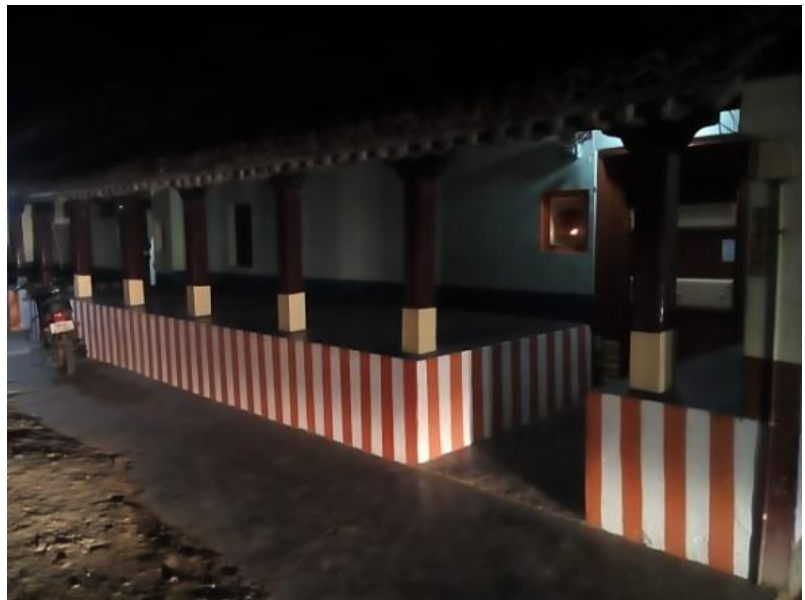

Figure 15. Agraharam House with Lamp

Source: Architect Vidyashankar.

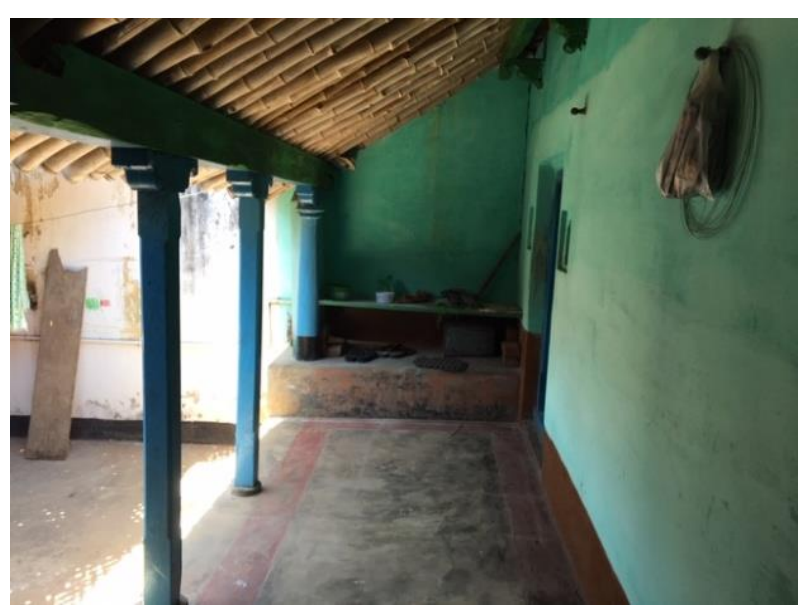

Figure 16. Thalavaram in an Agraharam House Source: Anjali Sadanand.

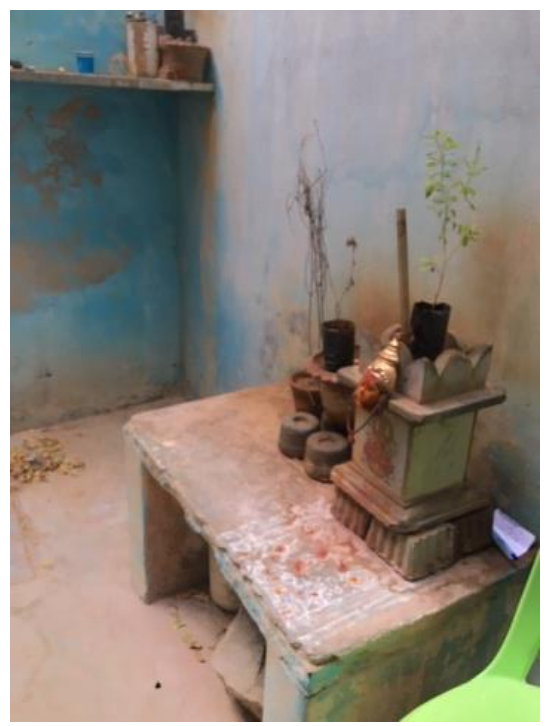

Figure 17. Thulsi Plant in Agraharam House, House 5. Source: Anjali Sadanand. 


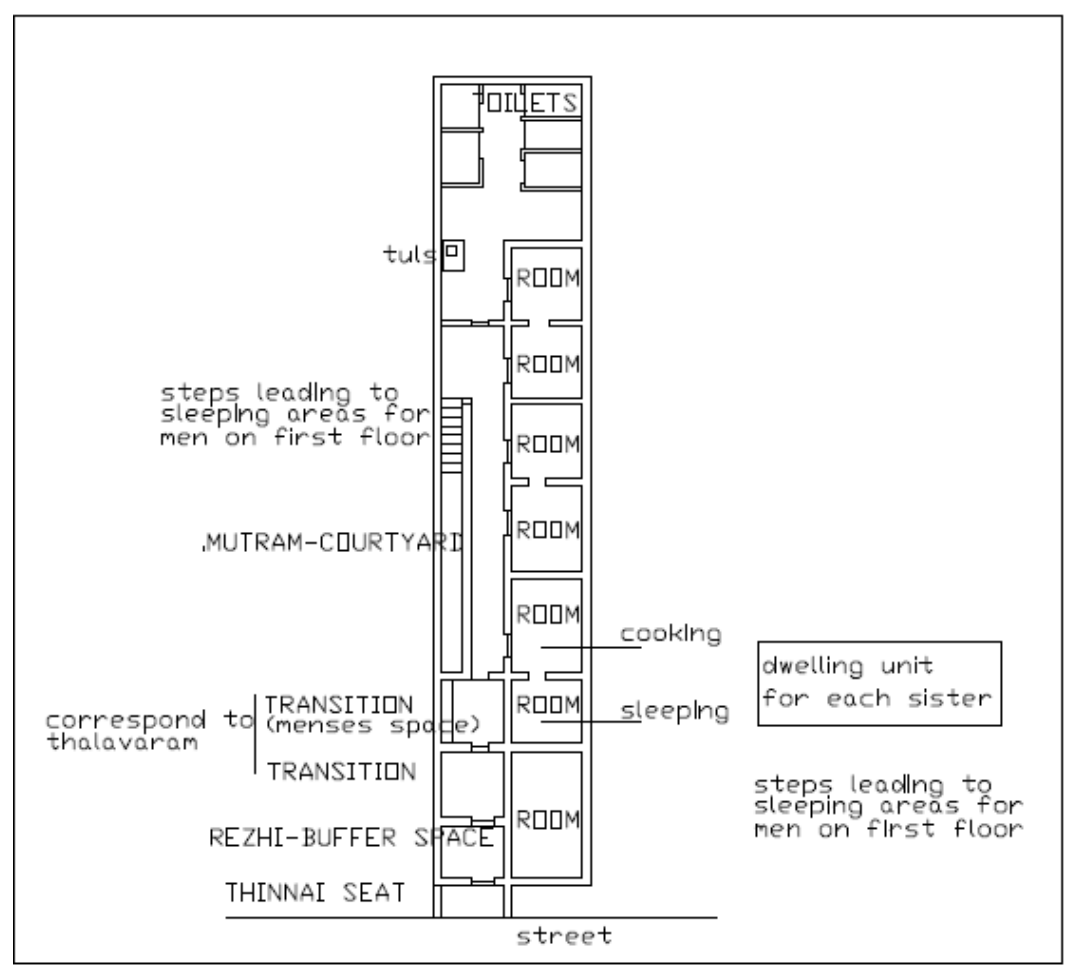

Figure 18. Plan of House 5

Source: Anjali Sadanand

The question arises as to how these fixed social constructs are maintained in an urban situation. House 5 (Figure 18) is the house of a Brahmin family in Chennai. The house is in close proximity to a temple as the men work in temple related posts, as cooks and priests. Due to paucity of space, combinations of spaces have resulted in a compact plan with origins in the agraharam plan typology. The house has a very narrow frontage. The plan is linear and follows the agraharam typology. It is two storeys. There are three sisters, who live in this house with their families; each sister has a unit which consists of a hall, a kitchen and a room with a separate bathroom. As the front is narrow, the plan is deep. The courtyard is narrow, approximately three feet wide and lets in light and gives access to the floor above. The similarity to the typology of agraharam house is in the provision and location of each unit and toilets within the social framework of their origins i.e., agraharam typology, but within the spatial constraints offered. A thinnai separates the house door from street and another room the rezhi of the rural counterpart is the next transition (Figure 19), but beyond this, is a room and space which is traversed to enter the central part of the house which is the women's space. This space leads to a narrow corridor with the courtyard on one side and gives entry to each unit; each unit has a hall with one side as cooking space and a door leading to a room. The corridor and front door are aligned to open into a small rear courtyard which houses a tulsi plant (Figure 17). This court corresponds to the second court of the agraharam typology and deals with housekeeping and services shared by the three sisters. The axis is then broken as it then leads to the end of the plot leading to a corridor from which bathing rooms and latrines are located. The central 
corridor is the neutral space which was earlier seen around the courtyard which connects all spaces. The kitchen is now a cooking space and at the far end of the hall; the hall leads to the broom for sleeping as in the earlier type. Taboos and customs are thus observed and maintained. Men sleep in the upper storey. The thinnai provides a seat for social interaction with neighbours and family.

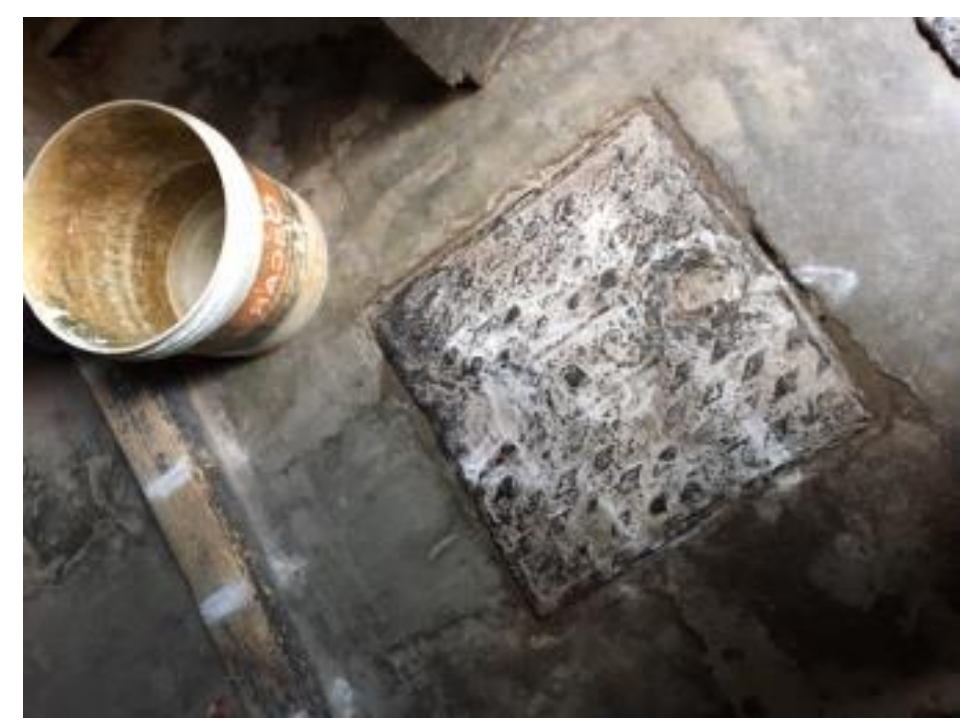

Figure 19. Entry Showing Kolam

Source: Anjali Sadanand.

House 6 (Figure 20) is a house built in the 1960's that shows a veneer of modernization but holds on to its traditional cultural norms seen in it thinnai, axis and rules on eating. The house is built in a large plot with a compound wall and has a large garden with trees. Transition from the street is through the garden. The house has a large "L" shaped verandah which has a low wall to delineate its boundary. Steps lead to its plinth and the verandah divides into a space for cane chairs and a flexible space for other activities. Immediately to the left of the entrance is a thinnai seat. Refer Figure 20. The owner is very proud of the thinnai as it is an emblem of cultural rootedness. The thinnai does not function as it does in the rural context but is more symbolic in its role. The front door is aligned to a window through which a tulsi plant is visible (Figure 21). The master bedroom leads off from the verandah. The verandah, Refer Figure 21, is a transition and an identifiable, labeled social space where all family functions are conducted and where the owner reads and socializes. It is her threshold space between the private bedroom and living room and the outside, but the verandahs serve as an interpretation of the function of the hall and thinnai. Whereas the hall in the rural counterpart climatologically made conditions comfortable, the garden in this case takes on the role of the courtyard as it offers ventilation light and the prospect of a view and privacy by virtue of its compound wall. There are no set women's spaces and the ritual of eating is maintained by locating the space of dining inside. The verandah hosts all events but eating. 


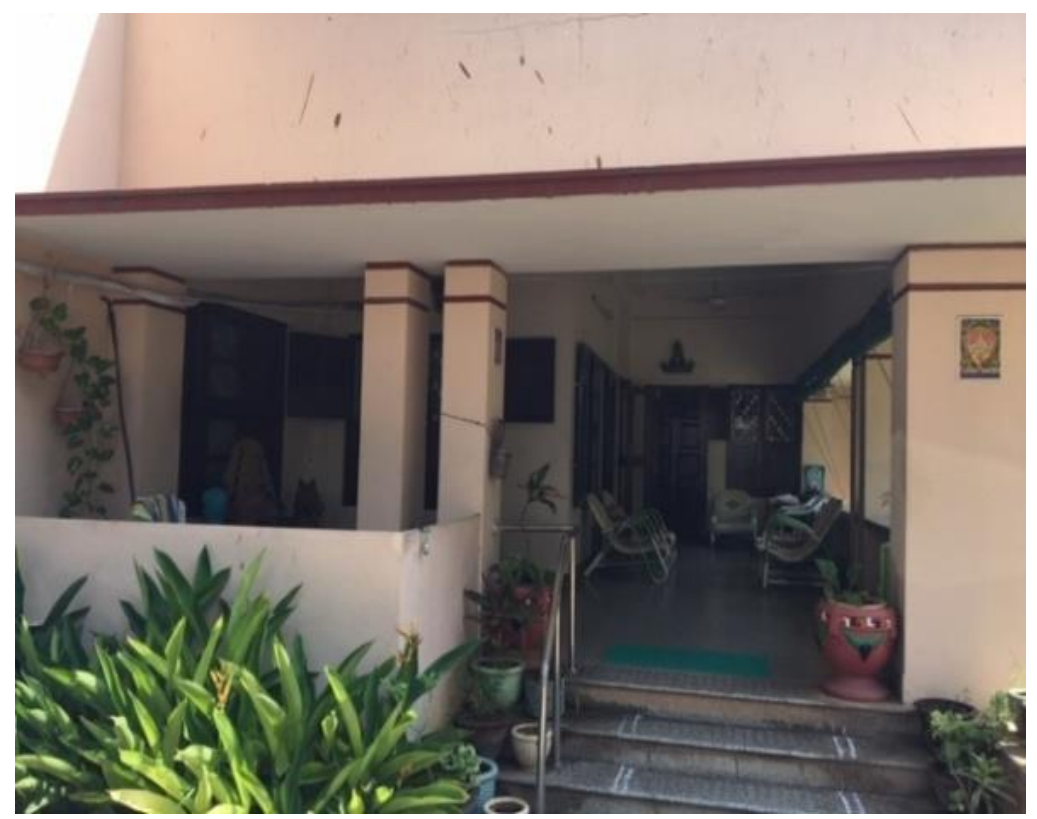

Figure 20. Entry Verandah and Thinnai of House 6

Source: Anjali Sadanand

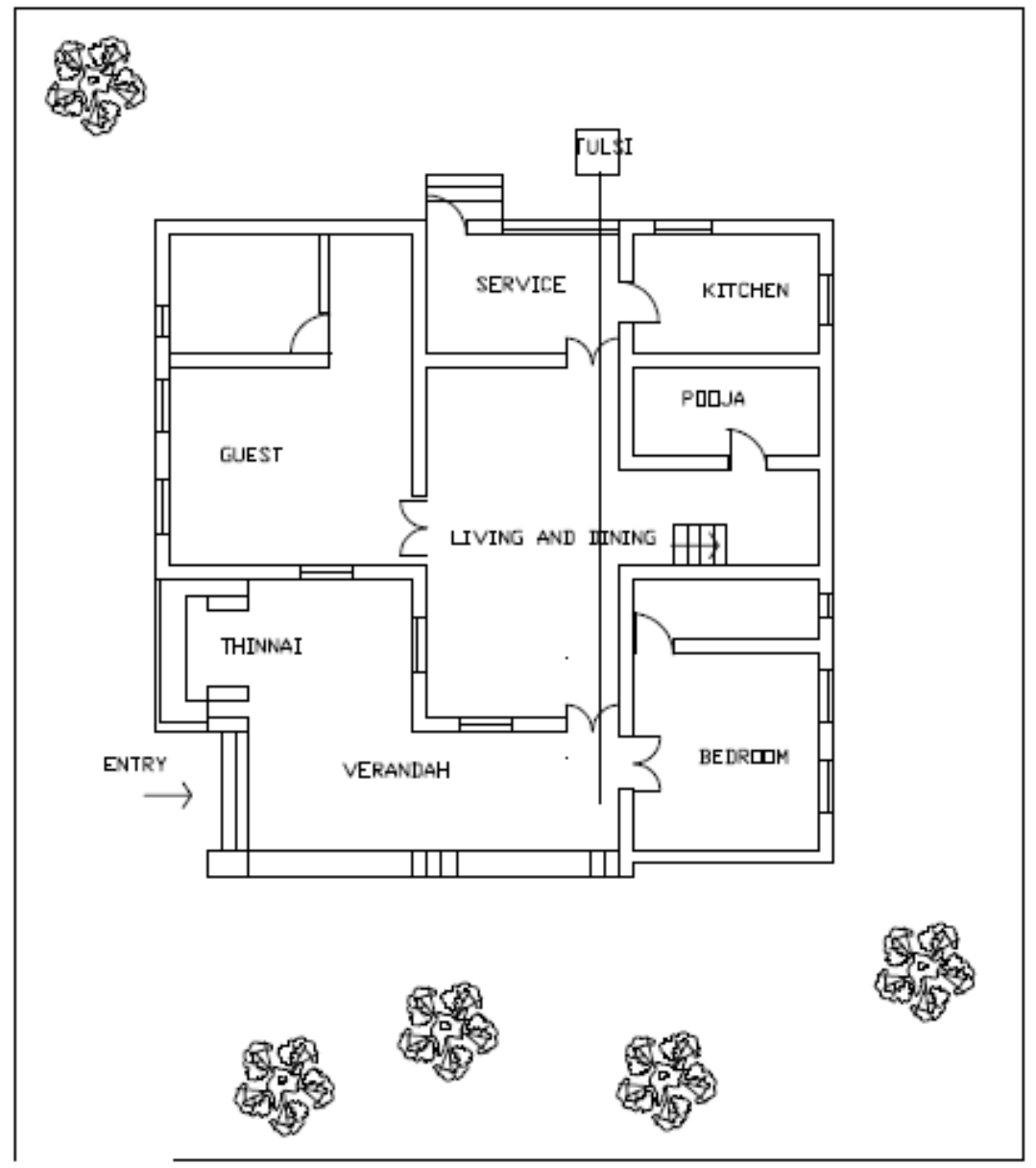

Figure 21. Plan of House 6 showing Entry Verandah and Thinnai Source: Anjali Sadanand 
House 7 (Figure 22) is an old house built 100 years ago but remodeled to suit modern needs (Figure 23). It belonged to a musician who lived in it with his family. The house is a typical house as described earlier modified slightly to be built in an urban setting. The house when it was originally built sat on several acres. It was approached by the front thinnai area which served as an open space with no walls on three sides with just a roof. Two identical thinnai or sloped seats were placed symmetrically on two corners like in the agraharam houses. Two symmetrically placed rooms led off from this space. In the early days the thinnai area was a mere transition space which leads to the rezhi. From the rezhi were steps that lead to the main hall above which was the owner's reception room or hall. Beyond the rezhi was another hall and beyond it kitchen, store and puja and bathrooms at the rear. To one side of the house were built two rooms approached by a side door which was the room for women with menses. A separate staircase led off through a transition space which led off the ground floor hall to an open terrace above where social interaction with the women could take place. Conventional cultural norms as seen and observed in the agraharam typology have been recreated but spread out over a larger area. The transition space is still the key moderator and convener of privacy, identity and hierarchy.

In the modern renovation of recent years the transition space has lost its potential to create boundaries and spatialise categories. In the new plan, the entry is on the side. One enters through a transition space to the ground floor hall which functions as living and dining. A bedroom is accessed from it. An open kitchen is visible from the dining and a smaller puja has been created. The ante space between hall and rear verandah has been remodeled into a television family space. Similarily, in front the central thinnai area has been converted to a family room and the inbuilt thinnai seats in the two corners have been absorbed, each into a bedroom. The corner bedrooms are fitted with attached bathrooms. The first floor plan is similar. The rezhi is the only ante space or transition in the house. Breaking down of social barriers, especially those related to gender spaces, has opened up space in the house. The Musri Subramaniam house shows a blurring of boundaries between categories of function. Compartmentalisation is more a requisite of the need for a comfortable environment for air conditioning than social division based on privacy. Our notion of privacy is redefined and relates to bedrooms. The rezhi acts as a transition which leads to an informal living area which leads to bedrooms. In effect the front of the house is the private space and with the entrance on the side the semi-private space is the entrance area and the living and dining. The side entry also creates a meandering walk and transition between public entry and house. 

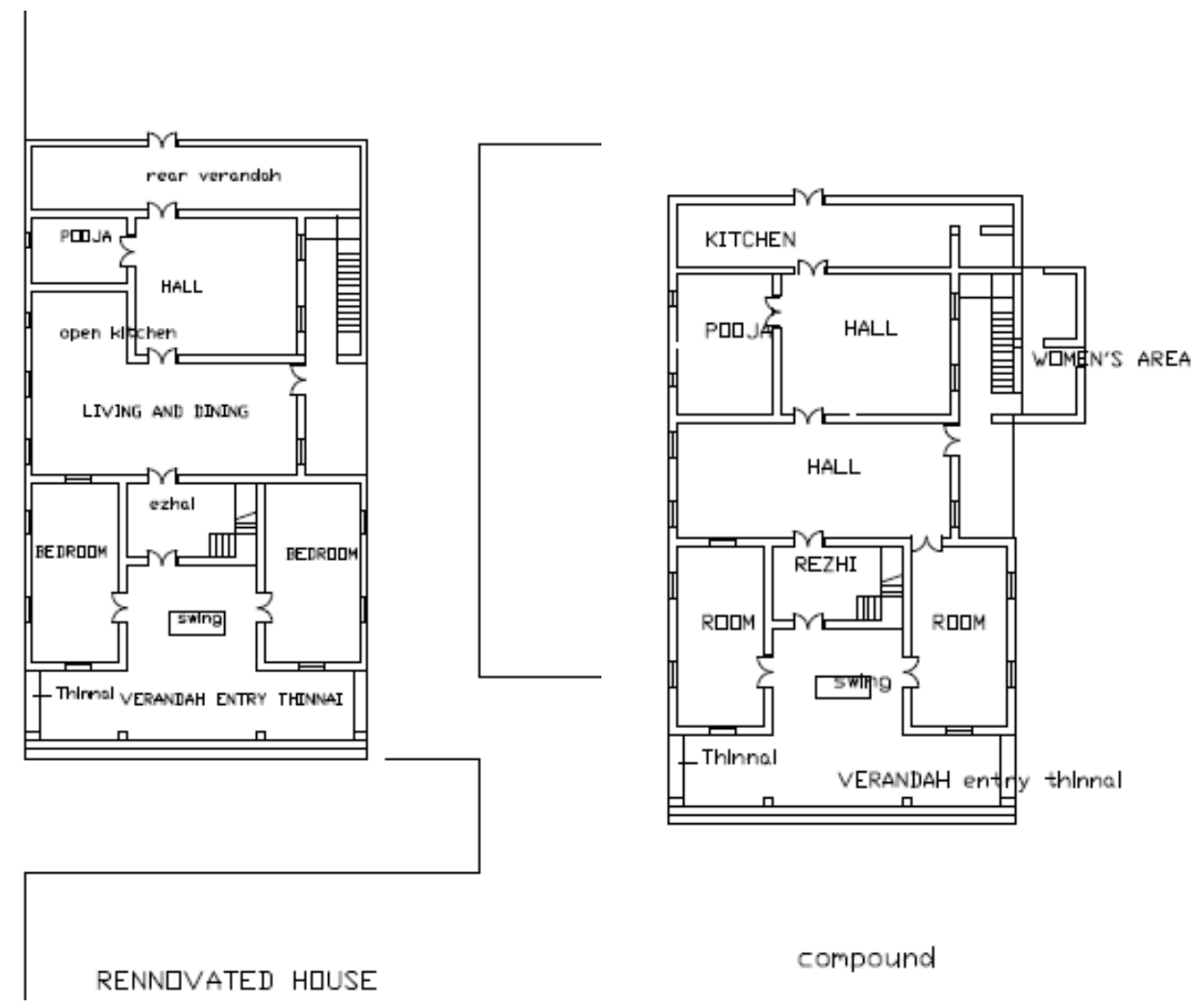

Figure 22. Musri Subramaniam House - Plans of House 7 Source: Anjali Sadanand.

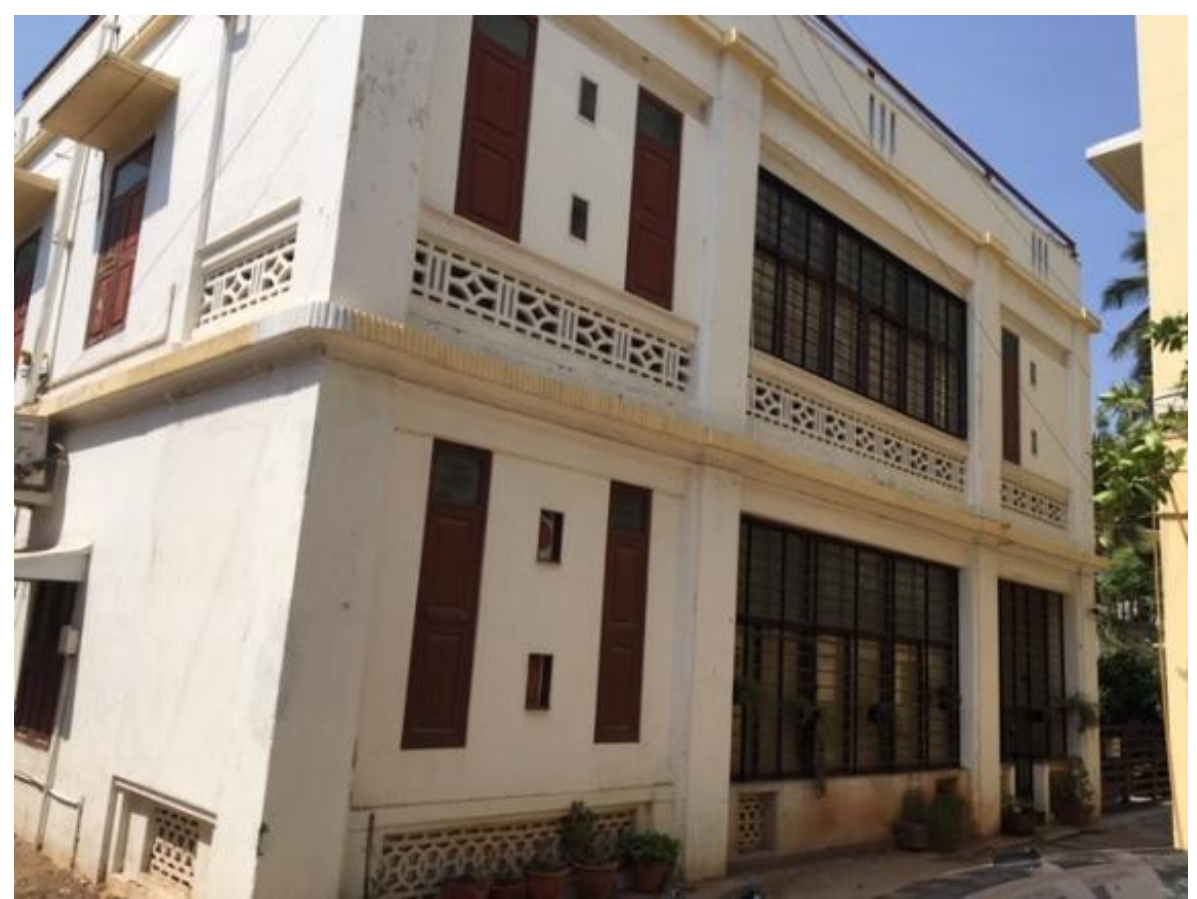

Figure 23. View of House as it Stands Today

Source: Anjali Sadanand. 
In House 8 (Figure 24), it can be seen that transition spaces add to hierarchical importance and build up a sequence of views like Corbusier's promenade to key spaces. The internal courtyard has been used as a prayer space and when not in use functions as part of the schemata of the house. Blinds give privacy when it is used.

Thresholds are significant and ornamented when there is a function. In an apartment or where there is a property boundary the gate marks the first point of entry. In Figure 24, the floor, as Yatin Pandya suggests, of the lobby is shown to be demarcated as a transition by creating an imaginary transition space in front of the entrance by the drawing of a kolam.

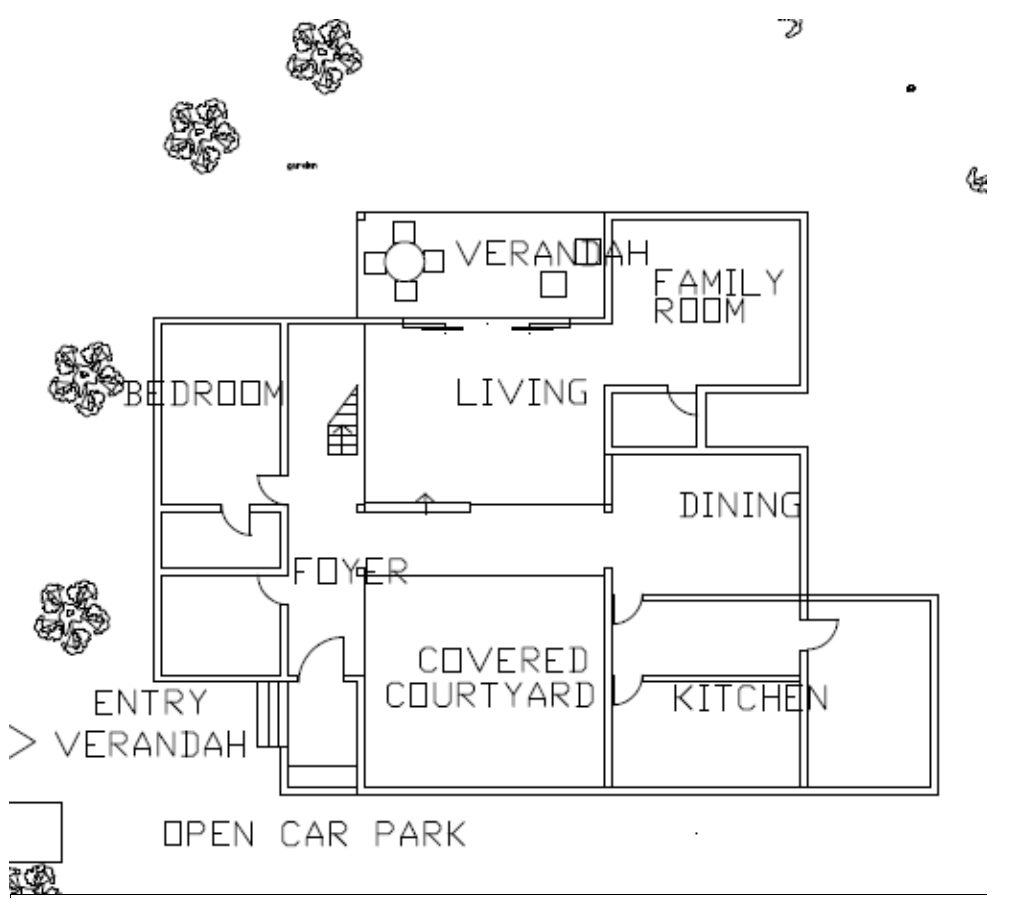

Figure 24. Plan of House 8

Source: Anjali Sadanand. 
Table 1. Comparative Analysis of Transition Spaces in Rural Houses

\begin{tabular}{|c|c|c|c|c|c|}
\hline 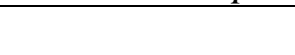 & \multicolumn{2}{|c|}{ House 1} & House 2 & House 3 & House 4 \\
\hline Context & \multicolumn{5}{|c|}{ Agraharam houses } \\
\hline Time Period & \multicolumn{5}{|c|}{ Approximately 100-150 years old but in current use } \\
\hline Modifications & \multicolumn{5}{|c|}{ Basically electrical and sanitary } \\
\hline Scale & \multicolumn{2}{|c|}{$\begin{array}{l}\text { Single courtyard and back yard for } \\
\text { cows }\end{array}$} & $\begin{array}{l}\text { Two small courtyards } \\
\text { and back yard for cows }\end{array}$ & $\begin{array}{c}\text { Three courtyard and } \\
\text { back yard for } \\
\text { cows }\end{array}$ & Three courtyards and back garden cows etc. \\
\hline Type & \multicolumn{5}{|c|}{ Agraharam with front and rear entry, basic rooms of thinnai, rezhi, hall, kitchen, pooja, room, cowshed and bathrooms, single storey } \\
\hline \multirow[t]{2}{*}{$\begin{array}{l}\text { Transition } \\
\text { Interior }\end{array}$} & $\begin{array}{l}\text { Front, thinnai or } \\
\text { verandah }\end{array}$ & South facing & $\begin{array}{l}\text { Front, thinnai or } \\
\text { Verandah } \\
\text { South facing }\end{array}$ & $\begin{array}{c}\text { Front, thinnai or } \\
\text { verandah south facing }\end{array}$ & $\begin{array}{c}\text { Golai with thinnai, south facing } \\
\text { Front, thinnai or verandah, south } \\
\text { Rezhi rectangular room with two doors on a north south } \\
\text { axis }\end{array}$ \\
\hline & \multirow{3}{*}{$\begin{array}{l}\text { Rezhi rectangular } \\
\text { room with two } \\
\text { doors on an north } \\
\text { south axis }\end{array}$} & \multirow{3}{*}{$\begin{array}{l}\text { Doors on a north } \\
\text { south axis }\end{array}$} & $\begin{array}{l}\text { Rezhi rectangular } \\
\text { room with two doors } \\
\text { on a north south axis }\end{array}$ & $\begin{array}{l}\text { Rezhi rectangular } \\
\text { room with two doors } \\
\text { on a north south axis }\end{array}$ & $\begin{array}{l}\text { 3.Rezhi rectangular room with two doors on a north } \\
\text { south axis }\end{array}$ \\
\hline \multirow[t]{2}{*}{$\begin{array}{l}\text { Middle Semi- } \\
\text { Public/Priv }\end{array}$} & & & $\begin{array}{c}\text { "C" shaped colonnade } \\
\text { around } \\
\text { courtyard } \\
\text { south and west and } \\
\text { north }\end{array}$ & $\begin{array}{l}\text { Verandah for second } \\
\text { courtyard }\end{array}$ & $\begin{array}{l}\text { Thalavaram, colonnade along south } \\
\text { Colonade along courtyard on west }\end{array}$ \\
\hline & & & & $\begin{array}{c}\text { 4.Verandah for } \\
\text { second courtyard }\end{array}$ & \\
\hline Rear Private & & & $\begin{array}{l}\text { 4. Verandah for rear } \\
\text { courtyard North }\end{array}$ & $\begin{array}{l}\text { 5.Verandah for rear } \\
\text { courtyard North }\end{array}$ & $\begin{array}{l}\text { Ante space to Women's room } \\
\text { Verandah for festival cooking } \\
\text { Verandah for cows, latrines. }\end{array}$ \\
\hline Transition Interior & $\begin{array}{l}\text { "C" shaped } \\
\text { narrow space } \\
\text { around courtyard } \\
\text { on three sides }\end{array}$ & $\begin{array}{l}\text { Doors on an } \\
\text { north south axis } \\
\text { south, north and } \\
\quad \text { west }\end{array}$ & $\begin{array}{c}\text { "L" shaped } \\
\text { Colonnade } \\
\text { Low parapet } \\
\text { Separates courtyard } \\
\text { from hall } \\
\end{array}$ & Around walled & Courtyard \\
\hline
\end{tabular}




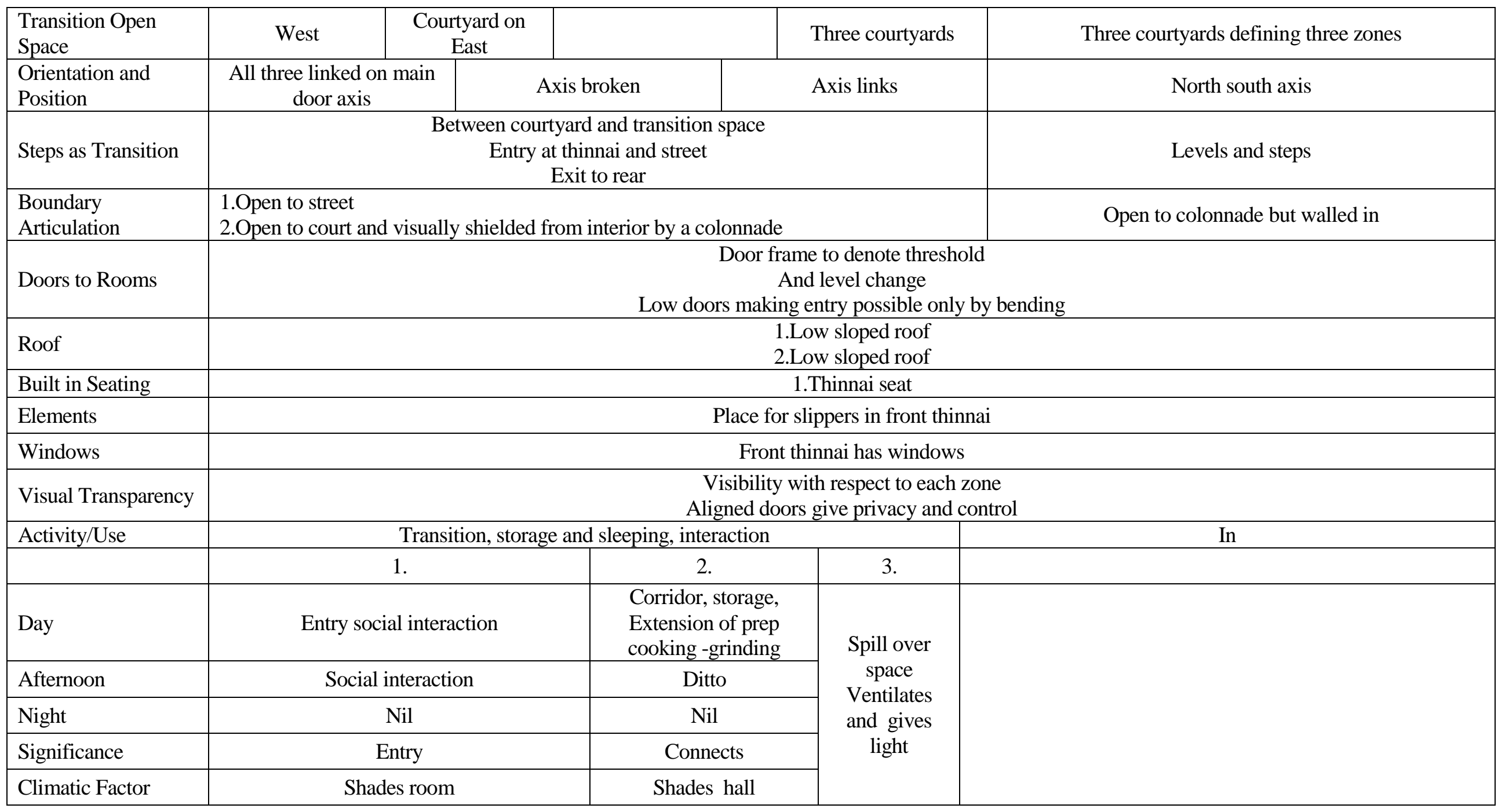




\begin{tabular}{|c|c|c|c|c|}
\hline $\begin{array}{l}\text { Architectural } \\
\text { Features }\end{array}$ & $\begin{array}{l}\text { - Thinnai } \\
\text { Door details of frame and casing, } \\
\text { threshold } \\
\text { - Entry step } \\
\text { Painting } \\
\text { - Kolam } \\
\text { - Columns of thinnai } \\
\text { - Coloured walls }\end{array}$ & $\begin{array}{l}\text { Column details and } \\
\text { articulation }\end{array}$ & Step details & $\begin{array}{l}\text { Common to all, except in House } 4 \text {. } \\
\text { Women have a room to rest in during menses and discuss } \\
\text { with family in part of the colonnaded transition space. } \\
\text { In House 3, they use the second courtyard. }\end{array}$ \\
\hline Phenomenological & Inviting, open connecting with context & $\begin{array}{l}\text { Feeling of enclosure by } \\
\text { low roof eaves creating } \\
\text { a layer around the } \\
\text { courtyard to create } \\
\text { spatial interaction with } \\
\text { hall and facilitate } \\
\text { movement }\end{array}$ & $\begin{array}{l}\text { Neutral } \\
\text { corridor }\end{array}$ & \\
\hline
\end{tabular}


Table 2. Comparative Analysis of Transition Spaces in Urban Houses

\begin{tabular}{|c|c|c|c|c|}
\hline & House 5 & House 6 & House 7 & House 8 \\
\hline Context & Agraharam houses & Independent house & Independent house & Independent house \\
\hline Time Period & $\begin{array}{c}\text { Approximately } 100-150 \text { years old } \\
\text { but in current use }\end{array}$ & & & \\
\hline Modifications & \multicolumn{4}{|c|}{ None } \\
\hline $\begin{array}{l}\text { Scale -apprx size of } \\
\text { Ground floor }\end{array}$ & Apprx 900 sft & Apprx $2000 \mathrm{sft}$ & Apprx $2200 \mathrm{sft}$ & Apprx $2500 \mathrm{sft}$ \\
\hline Type & $\begin{array}{l}\text { Agraharam typology, with front } \\
\text { entry, basic rooms of thinnai, } \\
\text { rezhi, hall, kitchen, bathrooms, } \\
\text { double storey. }\end{array}$ & $\begin{array}{l}\text { Independent house with verandah } \\
\text { and rooms leading off a living } \\
\text { dining .Certain traditional features } \\
\text { as in door in alignment with } \\
\text { window and tulsi plant and } \\
\text { verandah substituting for thinnai } \\
\text { and transition. }\end{array}$ & $\begin{array}{c}\text { Conventional rooms and sequencing } \\
\text { in an independent house with no } \\
\text { courtyard (and set in a large plot- } \\
\text { original) }\end{array}$ & $\begin{array}{l}\text { A modern house facing to the rear } \\
\text { garden with an entrance verandah. }\end{array}$ \\
\hline Transition Interior & $\begin{array}{l}\text { Front, thinnai or verandah, rezhi, } \\
\text { etc. }\end{array}$ & none & $\begin{array}{l}\text { Thinnai and Rezhi in the original } \\
\text { house and none in modernized } \\
\text { renovation. }\end{array}$ & $\begin{array}{l}\text { Series of transition buffer or } \\
\text { passages }\end{array}$ \\
\hline \multicolumn{5}{|l|}{ Front Public } \\
\hline $\begin{array}{l}\text { Middle Semi- } \\
\text { Public/Priv }\end{array}$ & Passage and courtyard & none & none & $\begin{array}{l}\text { Series of transitions to highlight } \\
\text { promenade. }\end{array}$ \\
\hline \multicolumn{5}{|l|}{ Rear Private } \\
\hline $\begin{array}{l}\text { Transition Open } \\
\text { Space }\end{array}$ & $\begin{array}{c}\text { Narrow interior courtyard and rear } \\
\text { yard }\end{array}$ & none & none & none \\
\hline $\begin{array}{l}\text { Orientation and } \\
\text { Position }\end{array}$ & $\begin{array}{l}\text { Entry door linked on axis to } \\
\text { outside through door opening. }\end{array}$ & $\begin{array}{l}\text { Entry door linked on axis to } \\
\text { outside, visual, and tulsi plant } \\
\text { through window. }\end{array}$ & $\begin{array}{l}\text { Entry door linked on axis to outside } \\
\text { through door opening in original } \\
\text { house. Door opening in line with a } \\
\text { window opening in renovated house. }\end{array}$ & $\begin{array}{l}\text { Door opening in line with a } \\
\text { window opening. }\end{array}$ \\
\hline Steps as Transition & Between street and thinnai & $\begin{array}{l}\text { Between verandah and entry } \\
\text { garden }\end{array}$ & $\begin{array}{l}\text { Between thinnai and entry garden in } \\
\text { original and none in renovated. }\end{array}$ & $\begin{array}{l}\text { Between verandah and entry } \\
\text { garden }\end{array}$ \\
\hline $\begin{array}{l}\text { Boundary } \\
\text { Articulation }\end{array}$ & $\begin{array}{c}\text { Open to street } \\
\text { Open to court and visually }\end{array}$ & Visually shielded by garden & Open to plot & $\begin{array}{l}\text { Shielded by verandah in front } \\
\text { Private garden in rear. }\end{array}$ \\
\hline
\end{tabular}




\begin{tabular}{|c|c|c|c|c|}
\hline & shielded & & & \\
\hline Doors to Rooms & $\begin{array}{l}\text { Door frame to denote threshold } \\
\text { And level change } \\
\text { Low doors making entry possible } \\
\text { only by bending }\end{array}$ & No alignment & No specific alignment in renovated & $\begin{array}{c}\text { Door itself can become a French } \\
\text { door and open up garden in rear to } \\
\text { living room } \\
\text { Visual connect to garden }\end{array}$ \\
\hline Roof & Flat roof & Flat roof & Flat roof & Flat roof \\
\hline Built in Seating & 1.Thinnai seat & Thinnai seat created & None & none \\
\hline \multicolumn{5}{|l|}{ Elements } \\
\hline Windows & No windows & $\begin{array}{c}\text { Front thinnai and verandah has } \\
\text { windows }\end{array}$ & $\begin{array}{l}\text { Front thinnai and verandah } \\
\text { Has windows in original not in } \\
\text { rennovated }\end{array}$ & no \\
\hline Visual Transparency & $\begin{array}{l}\text { Visibility with respect to each zone } \\
\text { Aligned doors give privacy and } \\
\text { control }\end{array}$ & Curtains on doors give privacy & $\begin{array}{l}\text { Visibility with respect to each zone } \\
\text { Aligned doors give privacy }\end{array}$ & No \\
\hline \multicolumn{5}{|l|}{$\begin{array}{l}\text { Activity/Use Day, } \\
\text { Night }\end{array}$} \\
\hline Courtyard & Ventilation and light & nil & nil & nil \\
\hline Thinnai/Verandah & $\begin{array}{l}\text { Social interaction day and evening } \\
\text { Talk to neighbours }\end{array}$ & $\begin{array}{l}\text { Entry and leave footwear. } \\
\text { Social space during day and } \\
\text { evening for social activities and } \\
\text { receiving guests and children } \\
\text { play space. }\end{array}$ & $\begin{array}{l}\text { Entry and leave footwear. } \\
\text { Social space during day and } \\
\text { evening for social activities and } \\
\text { receiving guests and children play } \\
\text { space. }\end{array}$ & Entry to house; leave footwear. \\
\hline
\end{tabular}




\section{Conclusions}

The paper has focused on transition spaces in South Indian houses. Transition spaces as employed exist, as in between spaces between realms as opposite as inside and outside and between interior spaces subtly using architectural elements to delineate them. The significance of the alignment of openings and transition spaces and the play with levels to further establish interval has proved an interesting area of study. For a comparison, please refer to Table 1. It has been noted that courtyards themselves form useful transition spaces and habitable spaces. In short the rural Hindu habitat has been shown to be carefully constructed spatially on a system of transition spaces which maintain cultural norms and formal relations. Transition spaces not only create privacy but make possible a sense of continuity of the house with the surrounding and context (Table 2). The house remains protected but within context of its geography and part of its community. It has been noted that a sense of modernization and deviation from the traditional Hindu norm as seen in the Christian house has shown a tendency towards compartmentalization of space while still maintain a distance and hierarchy from the street. In Musri Subramaniam's house an opening up of space was visible and the kitchen and eating areas which earlier were sacred spaces have become less ritually pure via the concept of open kitchens and the utilization of transition spaces to spatialise the notion of privacy to now specifically labeled sleeping spaces. Privacy, the division of public and private spaces and creation of identity as "placemaking" are thus shown consistent with house design today. Their articulation spatially may change but they are constants to our way of living. Points of entry are also vital as context plays a large role in entry and to ensure privacy entry must be carefully orchestrated.

In South India even with modernization and negotiating boundaries of common spaces as in apartments it is shown how identity is at all times sustained through articulation of thresholds ,through ornamentation on frame or symbolic references of personal space on floor.

To conclude transition spaces remain vital and essential to our living patterns.

\section{Acknowledgements}

Sincere thanks to Architect Vidyashankar and Architect Dhivyashree for their help while conducting the interviews. Sincere thanks to Mr Nagasubramanyan N.Swaminathan for valuable information and permitting me to visit his house (House 4).Thanks to Mrs Kalpagam for her description on lifestyle patterns in House 6 and Mr Musri Subramaniam's grandson for his information on House 7. 


\section{Bibliography}

Ananthalwar, M. A. A. Indian Architecture. Chennai: V. T. Iyer \& sons, n.d.

Asquith, L. and M. Vellinga. Vernacular Architecture in the Twenty-First Century. Great Britain: Taylor and Francis, 2006.

Boetteger, T. Threshold Spaces. Basel: Birkhauser, 2004.

Cooper, I. and B. Dawson. Traditional Buildings of India. London: Thames and Hudson, $1998,163$.

Desai, M. Wooden Architecture of Kerala. India: Mappin Publishing, 2018.

Hanson, J. Decoding Homes and Houses. Cambridge: Cambridge University Press, 1998.

Jain, K. Thematic Space in Indian Architecture. New Delhi: India Research Press, 2002.

Pandya, Y. Elements of Spacemaking. India: Mappin Publishing PvtLtd, 2007.

Raporport, A. House Form and Culture. USA: Prentice-Hall, 1969. 
